\title{
DETERMINAÇÃO DE COMPOSTOS CARBONÍLICOS EM DIFERENTES TIPOS DE CERVEJAS ARTESANAIS
}

Artur Santos Bispo1; Ingrid Marcela Melo Cardozo²; Jailson B. de Andrade3; Jeancarlo Pereira dos Anjos ${ }^{4}$

${ }^{1}$ Centro Universitário SENAI CIMATEC - Avenida Orlando Gomes, Piatã, 416550010 - Salvador, BA - Brasil.

Resumo: Compostos carbonílicos podem estar presentes em cervejas artesanais, sendo provenientes do processo de fermentação. Este trabalho teve como objetivo identificar e quantificar esses compostos em diferentes tipos de cervejas artesanais utilizando HPLC-DAD. As amostras foram derivatizadas com solução de 2,4-DNPH, em meio ácido. Após, as amostras foram injetadas no sistema cromatográfico. A cerveja clara tipo pilsen apresentou a maior concentração total de compostos carbonílicos $\left(13,72 \mathrm{mg} \mathrm{L}^{-1}\right)$. O aceltaldeído foi o C.C que apresentou as maiores concentrações (até 7,60 $\mathrm{mg} \mathrm{L}^{-1}$ ) nas amostras analisadas. Torna-se necessário um acompanhamento da concentração destas substâncias na bebida devido aos aspectos toxicológicos associados à ingestão dos mesmos em bebidas alcoólicas.

Palavras-Chave: Cerveja, Compostos Carbonílicos, Cromatografia, HPLC.

\section{DETERMINATION OF CARBONYL COMPOUNDS IN DIFFERENT TYPES OF CRAFT BEERS}

\begin{abstract}
Carbonyl compounds may be present in craft beers, coming from the fermentation process. This work aimed to identify and quantify carbonyl compounds in different types of craft beers using HPLC-DAD. The samples were derivatized with 2,4dinitrophenylhydrazine solution, in acid medium. Afterwards, the samples were injected into the chromatographic system. Pilsen beer presented the highest total concentration of carbonyl compounds $\left(13.72 \mathrm{mg} \mathrm{L}^{-1}\right)$. Aceltaldehyde was the carbonyl compound that presented the highest concentrations (up to $7.60 \mathrm{mg} \mathrm{L}^{-1}$ ) in the samples analyzed. Monitoring of the concentration of these substances in the craft beers is necessary due to the toxicological aspects associated with their ingestion in alcoholic beverages.
\end{abstract}

Keywords: Beer, Carbonyl Compounds, Chromatography, HPLC 


\section{INTRODUÇÃO}

É fato conhecido que a cerveja é uma das bebidas mais consumidas em escala global, abrangendo um vasto público alvo. Observa-se um crescente aumento no mercado de produção e consumo de cervejas artesanais tornando necessário um acompanhamento da qualidade final do produto. Sendo assim, evidencia-se a importância de ter conhecimento sobre a composição química da bebida, principalmente pelo fato de alguns dos compostos presentes na mesma serem, potencialmente prejudiciais à saúde do consumidor. ${ }^{[1]}$

A produção de cerveja, basicamente, é dada a partir da fermentação do mosto proveniente do malte, o qual ocorre devido à presença de leveduras da espécie Saccharomyces cerevisiae, produzindo como produtos principais o álcool etílico $\left(\mathrm{C}_{2} \mathrm{H}_{5} \mathrm{OH}\right)$ e o dióxido de carbono $\left(\mathrm{CO}_{2}\right)$, além de outras substâncias que compõem o flavor característico da bebida. Além disso, com a adição do lúpulo, ocorre a formação dos principais compostos responsáveis pelo sabor e aroma da bebida. ${ }^{[2,3]}$

Entretanto, no processo de fabricação da cerveja, além da produção das substâncias que compõem o flavor característico da bebida, ocorre também a formação de compostos secundários dentre os quais alguns podem ser prejudiciais à qualidade do produto final. Dentre tais compostos, os compostos carbonílicos (CC) apresentam grande importância, tendo em vista sua capacidade de alteração nas características sensoriais da cerveja e, principalmente, o potencial toxicológico que os mesmos possuem. Visto isso, a importância em ter ciência das especificações e possíveis riscos que cada um dos compostos analisados pode trazer ao organismo humano torna-se evidente. ${ }^{[1,4]}$

Diante ao exposto, este trabalho teve como objetivo identificar e quantificar compostos carbonílicos em diferentes tipos de cervejas artesanais utilizando a cromatografia líquida de alta eficiência, com o intuito de avaliar a qualidade do produto final quanto à presença dessas substâncias.

\section{METODOLOGIA}

Amostras de cervejas artesanais $(n=13)$ de diferentes tipos foram adquiridas no comércio da cidade de Salvador-BA, sendo elas, respectivamente: Cerveja de trigo leve do tipo Weiss, Cerveja extra tipo pale ale, Cerveja extra escura tipo vienna lager, Cerveja forte escura índia pale ale, Cerveja clara tipo pilsen, Cerveja trigo extra com coentro e aroma de laranja, Cerveja forte escura porter com café, Cerveja forte escura tipo bock, Cerveja forte escura com aroma de baunilha ale, Cerveja Pilsen, Bebida alcoólica mista, Cerveja forte imperial I.P.A e Cerveja puro malte leve.

As análises dos compostos carbonílicos foram realizadas em um cromatógrafo líquido de alta eficiência com detector de arranjo de diodos (HPLC-DAD) da marca Shimadzu, equipado com uma unidade de bombeamento de solvente quaternária (LC20AT), um injetor automático (SIL-20AHT), desgaseificador (DGU-205), forno para coluna (CTO-20A) e uma interface controladora (CBM-20A). A separação cromatográfica foi realizada utilizando uma coluna da marca Shimadzu $(250 \mathrm{~mm} x$ 
4,6mm), acoplada à uma pré-coluna C18 da marca Hexis $(12,6 \mathrm{~mm} \times 4,6 \mathrm{~mm})$. Água (solvente A) e acetonitrila (solvente B) foram utilizados como fase móvel, com as análises sendo realizadas por meio de um gradiente de eluição: $0-2,0$ min $(45 \% \mathrm{~B}$ a $75 \%$ B); $2,0-10,0 \min (75 \%$ B); 10,0 - 23,0 min (75\% B a 100\% B); 23,0 - 25,0 min $(100 \%$ B); $25,0-27,0$ min (100\% B a $50 \%$ B); $27,0-33,0$ min (50\% B a $45 \%$ B); 33,0 $-33,5 \mathrm{~min}(45 \% \mathrm{~B})$. As análises foram realizadas com o forno na temperatura de $40^{\circ} \mathrm{C}$, fluxo de $1,0 \mathrm{~mL} \mathrm{~min}^{-1}$ e em comprimento de onda de $365 \mathrm{~nm}$.

Precedendo os processos de análise das amostras, fez-se necessário o procedimento de recristalização do 2,4-DNPH (2,4-dinitrofenilidrazina), composto utilizado na reação de derivatização das amostras de cervejas artesanais, em acetonitrila. A 2,4-DNPH reage com os compostos carbonílicos presentes nas amostras, tornando-os detectáveis pelo detector de arranjo de diodos utilizado no sistema cromatográfico, por meio da formação das respectivas hidrazonas dos compostos carbonílicos. Após a recristalização da 2,4-DNPH, foi preparadauma solução estoque da mesma $(0,081 \%)$, em acetonitrila, para que fosse utilizada no processo de preparo das amostras de cervejas artesanais. [5]

A derivatização das amostras foi realizada pela reação química entre a 2,4_DNPH e os compostos carbonílicos presentes nas amostras, em meio ácido. Para isso, foram adicionados $375 \mu \mathrm{L}$ de 2,4-DNPH $(0,081 \%)$ e $18 \mu \mathrm{Ldeácido} \mathrm{fosfórico}(85 \%)$ em cada uma das amostras de cerveja $(1500 \mu \mathrm{L})$, de modo que se tinha um volume final de $1893 \mu \mathrm{L}$. Em seguida, a mistura foi colocada em banho ultrassônico, por 20 min, filtrada em filtro de Teflon $(0,45 \mu \mathrm{m})$ e injetada no sistema cromatográfico.

Para a quantificação dos compostos carbonílicos, foram construídas curvas analíticas a partir de uma solução padrão contendo uma mistura dos seguintes compostos: formaldeído, acetaldeído, acetona, acroleína, propionaldeído, metacroleína, isobutiraldeído, butiraldeído, benzaldeído, cliclohexanona, valeraldeído, $m$-tolualdeído, o-tolualdeído, hexanal e heptanal. As curvas analíticas apresentaram concentrações que variaram de $2 \mathrm{\mu g} \mathrm{L}^{-1}$ a $100 \mu \mathrm{g} \mathrm{L}^{-1}$, preparadas por meio de diluições sucessivas da solução estoque $\left(1000 \mu \mathrm{g} \mathrm{L}^{-1}\right)$, em acetonitrila. Antes da preparação das curvas analíticas, realizou-se uma avaliação de dois solventes (etanol $40 \%$ e acetonitrila) que poderiam ser utilizados nas respectivas diluições da solução padrão dos CC, afim de avaliar a influência da graduação alcoólica das bebidas no sinal analítico. Dessa forma, optou-se pelo uso da acetonitrila na preparação das curvas, uma vez que os resultados para ambos os solventes foram significativamente próximos.

Todas as amostras e padrões foram injetados em triplicata no sistema cromatográfico.

\section{RESULTADOS E DISCUSSÃO}

As Figuras 1 e 2 mostram, respectivamente, o cromatograma resultante da análise de um padrão de compostos carbonílicos e outro de uma das cervejas artesanais. 
Figura 1: Cromatograma do padrão de compostos carbonílicos com concentração de 40 ppb

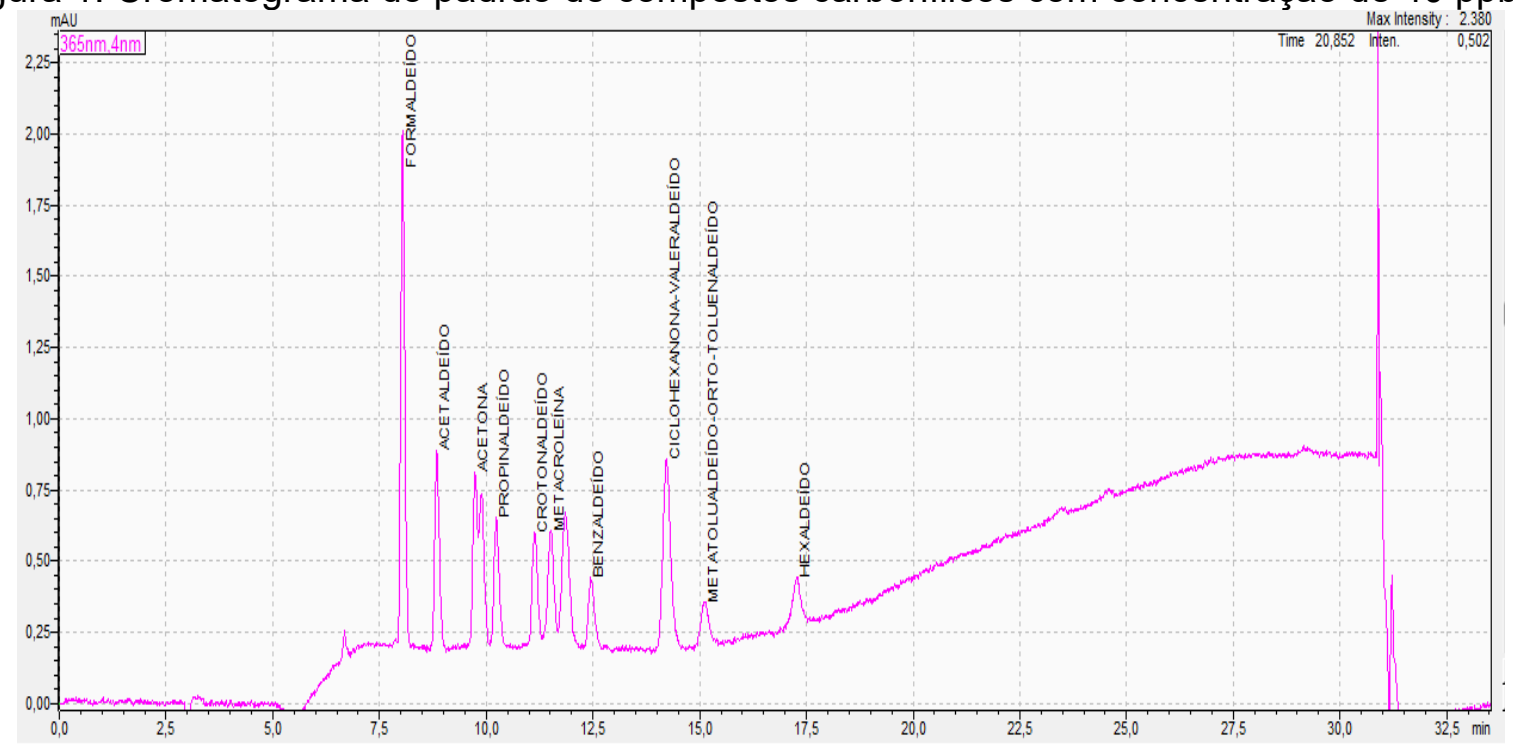

Figura 2: Cromatograma de uma das amostras de cervejas artesanais

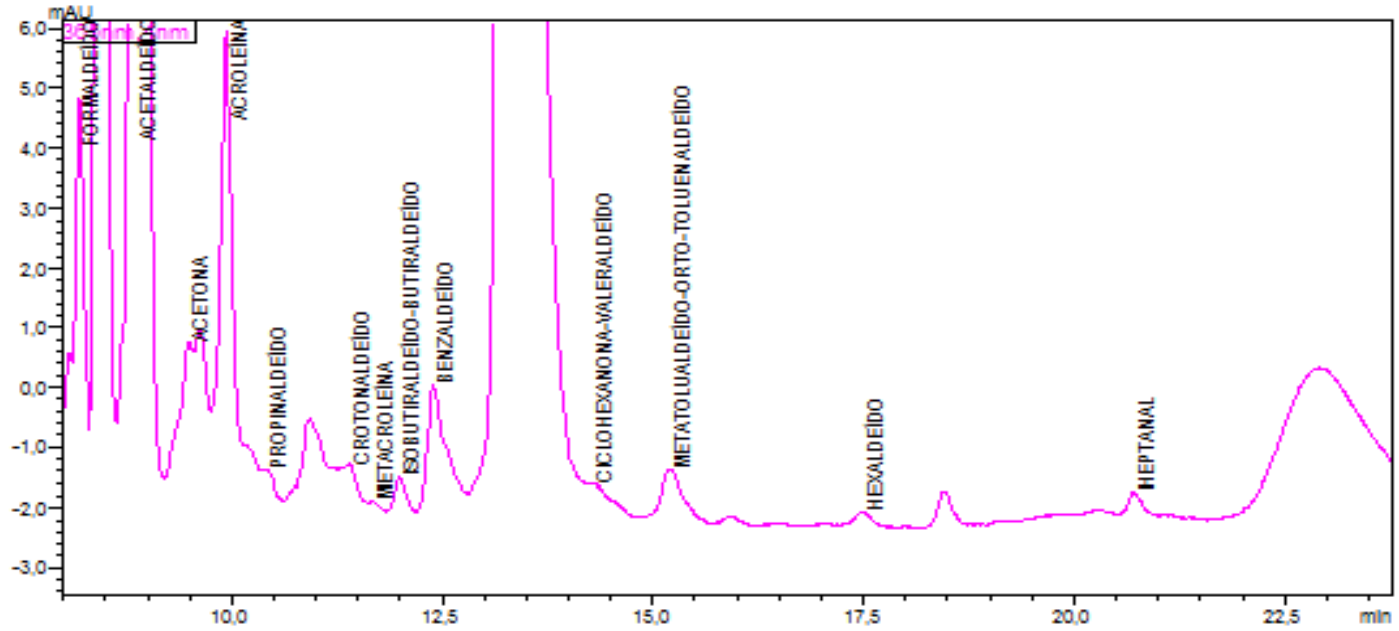

A Figura 3 mostra que a graduação alcoólica não foi um fator que promovesse comprometimento do sinal analítico durante a construção das curvas analíticas e posterior quantificação dos CC nas amostras de cervejas artesanais.

Figura 3 - Avaliação de dois solventes diferentes (etanol $40 \%$ e acetonitrila) na preparação das soluções padrão dos compostos carbonílicos. Identificação dos compostos: 1formaldeído; 2- acetaldeído; 3- acetona; 4- acroleína; 5- propionaldeído; 6- crotonaldeído; 7metacroleína; 8- isobutiraldeído + butiraldeído; 9- benzaldeído; 10- cicloexanona + valeraldeído; 11-o-tolualdeído + $m$-tolualdeído; 12- hexaldeído; 13- heptanal. 


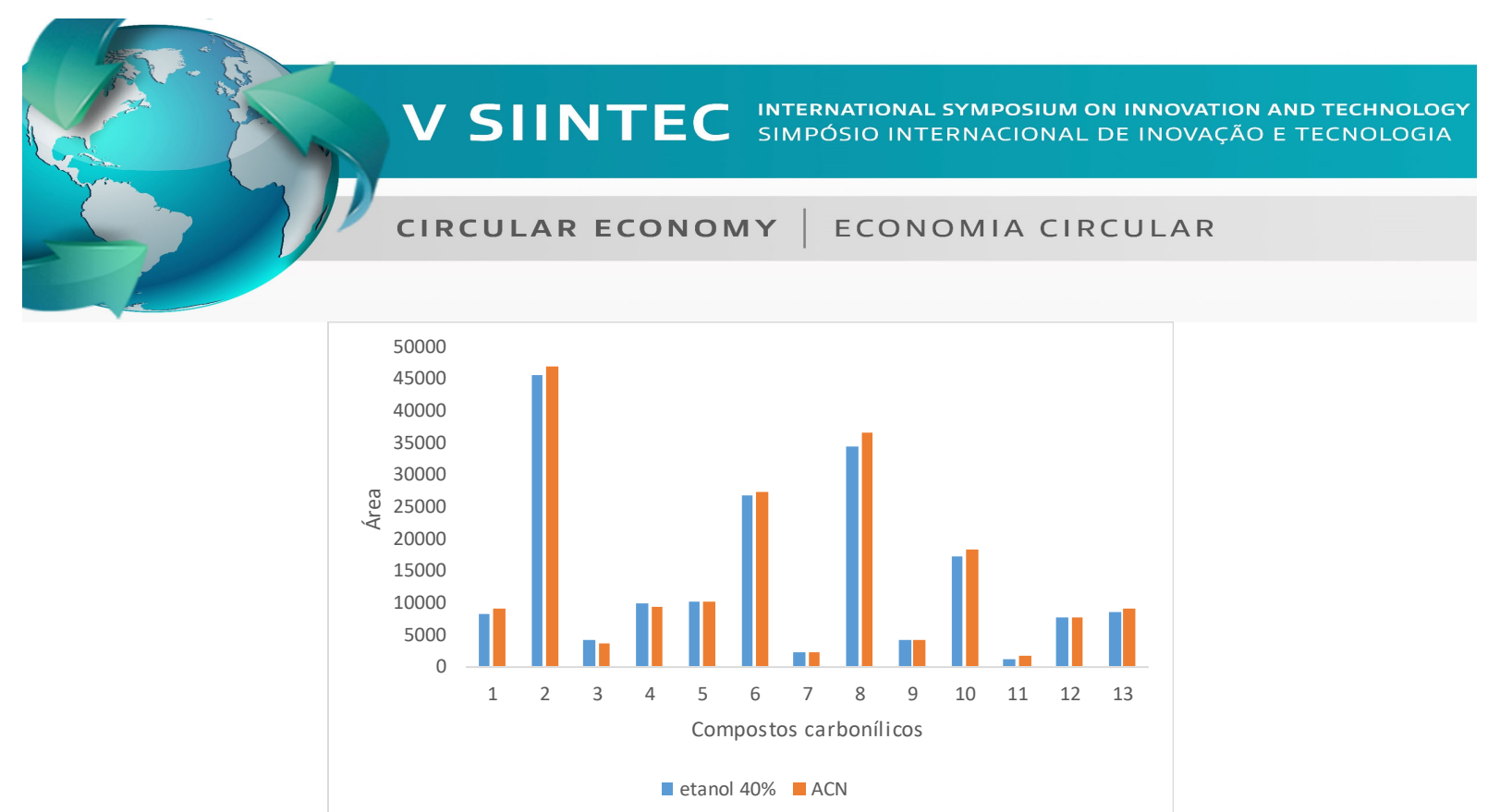

As concentrações dos CC identificados nas amostras de cervejas artesanais analisadas estão apresentadas na Tabela 1.

Tabela 1 - Faixa de concentração dos compostos carbonílicos identificados em amostras de cervejas artesanais

\begin{tabular}{|c|c|c|c|}
\hline Composto carbonílico & Faixa $\left(\mathrm{mg} \mathrm{L}^{-1}\right)^{*}$ & Composto carbonílico & Faixa $\left(\mathrm{mg} \mathrm{L}^{-1}\right)^{*}$ \\
\hline formaldeído & $0,20-1,45$ & isobutiraldeído + butiraldeído & ND - 0,03 \\
\hline acetaldeído & $N D-7,60$ & benzaldeído & $N D-1,30$ \\
\hline acetona & ND & cicloexanona + valeraldeído & $N D-0,11$ \\
\hline acroleína & $N D-3,54$ & $m$-tolualdeído + o-tolualdeído & $N D-2,85$ \\
\hline propionaldeído & $N D-0,15$ & hexaldeído & $N D-0,12$ \\
\hline metacroleína & $N D-2,35$ & heptanal & ND $-7,20$ \\
\hline
\end{tabular}

${ }^{*} \mathrm{ND}=$ não detectado

O aceltaldeído foi o composto carbonílico que apresentou as maiores concentrações dentre os compostos analisados, como evidenciado nas amostras 5 , 6 e 12 (Cerveja clara tipo pilsen, Cerveja trigo extra com coentro e aroma de laranja, Cerveja forte imperial I.P.A), com concentrações de $7,60 \mathrm{mg} \mathrm{L}^{-1}, 4,93 \mathrm{mg} \mathrm{L}^{-1}$ e 5,35 $\mathrm{mg} \mathrm{L}^{-1}$, respectivamente. Foi possível notar que o acetaldeído foi o que estava presente com maior frequência nas amostras analisadas. Este composto,quando em grandes concentrações, apresenta características tóxicas ao organismo, tendo em vista que o mesmo tem demonstrado um potencial embriotóxico, teratogênico e mutagênico. Além disso, a substância tem forte ligação com a ocorrência de intoxicação alcoólica, tornado evidente a importância no controle de sua concentração em bebidas alcoólicas. Apesar de não haver um limite máximo estabelecido para concentração de acetaldeído em cervejas, outras bebidas são regulamentadas pela legislação brasileira, tais como aguardente $(30 \mathrm{mg} / 100 \mathrm{~mL}$ de álcool anidro), conhaque $(40 \mathrm{mg} / 100 \mathrm{~mL}$ de álcool anidro), destilado simples de uva $(40 \mathrm{mg} / 100 \mathrm{~mL}$ de álcool anidro). ${ }^{[1]}$

Outro composto em destaque nas amostras foi o heptanal, visto que, embora não tenha apresentado níveis de concentração altos, nas amostras 8 e 9 (Cerveja forte escura tipo bock e Cerveja forte escura com aroma de baunilha Ale), o mesmo apresentou concentrações relativamente maiores que as demais amostras, sendo5,14 $\mathrm{mg} \mathrm{L}^{-1}$ e $7,20 \mathrm{mg} \mathrm{L}^{-1}$, respectivamente. 
Com relação aos tipos de cervejas artesanais analisadas, a amostra 5 (Cerveja clara tipo pilsen) apresentou a maior concentração total de compostos carbonílicos $\left(13,72 \mathrm{mg} \mathrm{L}^{-1}\right.$ ), seguido pelas amostras 12 (Cerveja forte imperial I.P.A), com 9,37 mg $\mathrm{L}^{-1}$ e 9 (Cerveja forte escura com aroma de baunilha ale), com $9,34 \mathrm{mg} \mathrm{L}^{-1}$. Por outro lado, a amostra 2 (Cerveja extra tipo Pale Ale), mostrou a menor concentração de carbonílicos totais $\left(0,24 \mathrm{mg} \mathrm{L}^{-1}\right)$ dentre as amostras analisadas, cerca de 10 vezes menor que a amostra 10 (Cerveja Pilsen) que apresentou a segunda menor concentração total de CC $\left(2,77 \mathrm{mg} \mathrm{L}^{-1}\right)$.

Também é possível notar que, de um modo geral, o propionaldeído, acetona, metacroleína, benzaldeído, ciclohexanona, valeraldeído e heptanal, apresentaram concentrações significativamente baixas, sendo que alguns destes compostos não foram detectados nas amostras analisadas.

\section{CONCLUSÃO}

Pode-se inferir que por meio de um método simples, foi possível identificar e quantificar compostos carbonílicos em cervejas artesanais de diferentes tipos. Devido à identificação da presença de um número relativamente alto de compostos carbonílicos identificados nas amostras de cervejas artesanais, torna-se necessário um acompanhamento da concentração destas substâncias na bebida devido aos aspectos toxicológicos associados à ingestão dos mesmos em bebidas alcoólicas.

\section{Agradecimentos}

Os autores agradecem ao Centro Universitário SENAI CIMATEC pela oportunidade da iniciação científica voluntária e pela disponibilização do espaço físico para a execução das atividades experimentais.

\section{REFERÊNCIAS}

1AZEVÊDO, Luciana; REIS, Marina; DA SILVA, Luciana; ANDRADE, Jailson. Efeito da presença e concentração de compostos carbonílicos na qualidade de vinhos. Química Nova, v. 30, n. 8, p. 1968-1975, 2007.

${ }^{2}$ RABELLO, Flávia. Produção de cerveja. Revista Agrogeoambiental - p. 145-153, dezembro 2009.

${ }^{3}$ GALLO, Claudio; CANHOS, Vanderlei. Determinação da microbiota bacteriana de mosto e de dornas de fermentação alcoólica. FEA-USP, 1989.

${ }^{4}$ ROSA, Natasha; AFONSO, Júlio Carlos. A química da cerveja. Química Nova na Escola,v. 37, n. 2, p. 98-105, 2015.

${ }^{5}$ SILVA, T. O. Estudo da emissão de aldeídos e outros COV por óleo de dendê e soja, em diferentes condições, sob aquecimento a temperatura de processos de fritura. 2007. Dissertação (Mestrado em Química - Universidade Federal da Bahia). 


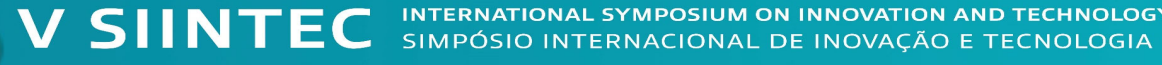

